\title{
Evaluation of the SeaWiFS and MODIS Chlorophyll a Algorithms Used for the Northern South China Sea during the Summer Season
}

\author{
Yanli Pan ${ }^{1,2}$, Danling Tang ${ }^{1,2, *}$, and Dehe Weng ${ }^{2,3}$ \\ ${ }^{1}$ Research Center of Remote Sensing on Marine Ecology and Environment, LED, South China Sea \\ Institute of Oceanology, Chinese Academy of Sciences, Guangzhou,China \\ ${ }^{2}$ The Graduate School of Chinese Academy of Sciences, Beijing, China \\ ${ }^{3}$ Beijing MRI Center for Brain Research, Institute of Biophysics, Chinese Academy of Sciences, Beijing, China
}

Received 9 October 2009, accepted 11 February 2010

\begin{abstract}
The present study made evaluations of SeaWiFS-derived and MODIS-derived Chlorophyll a (Chl a) concentrations in the Northern South China Sea (NSCS), using in situ data collected during two research cruises which were conducted during the summer of 2004 (September 18 to October 8 ) and 2007 (August 10 to 29). The data of $\pm 48 \mathrm{~h}$ and $3 \times 3$ pixels were used for the comparison between satellite and in situ $\mathrm{Chl}$ a data, and the results reveal a systematic overestimation of Chl a concentration by National Aeronautics and Space Administration (NASA) global algorithms (OC2v4, OC4v4, and OC3M). The RMSEs of the selected algorithms are larger than 0.35 except OC2_D'Ortenzio (one regional algorithm for the Mediterranean Sea). The overestimation seems to correlate with numerous $(\approx 77 \%)$ low Chl a concentration $\left(<0.1 \mathrm{mg} \mathrm{m}^{-3}\right)$ due to the oligotrophic characteristics of the South China Sea (SCS) in summer, and to correlate with the error in atmosphere correction introduced by aerosols. Therefore, the OC2 and OC4 algorithms for SeaWiFS and OC3M algorithm for MODIS are adapted to NSCS by fitting the satellite data set to in situ Chl a data in NSCS. With the new coefficients based on our field data, the regional version of the three algorithms (TP series) showed good performance with RMSE values of $0.245,0.245$, and 0.288 respectively, which were slightly higher than the algorithm "noise" (0.222 in RMSE). Those TP series algorithms may be considered preliminary due to the relatively small number of available in situ data, and they are suitable in summer season in NSCS.
\end{abstract}

Key words: Oligotrophic, Chlorophyll a, Algorithm, SeaWiFS, MODIS, Northern South China Sea

Citation: Pan, Y., D. Tang, and D. Weng, 2010: Evaluation of the SeaWiFS and MODIS Chlorophyll a algorithms used for the Northern South China Sea during the summer season. Terr. Atmos. Ocean. Sci., 21, 997-1005, doi: 10.3319/TAO.2010.02.11.01(Oc)

\section{INTRODUCTION}

Chlorophyll a (Chl a) concentration, a proxy for phytoplankton abundance, is a valuable indicator of the marine ecosystem, and satellite remote sensing is the only way at present to take frequent measurements of $\mathrm{Chl}$ a at regional and ocean-basin scales (Richardson et al. 2004). Studies on Chl a concentrations in the South China Sea (SCS) have been carried out using satellite sensors including the Coastal Zone Color Scanner (CZCS)(Tang et al. 1998), Ocean Color and Temperature Scanner (OCTOBERS)(Tang et al. 2002, 2003), Sea-viewing Wide Field-of-view Sensor (SeaWiFS) (Tang et al. 2004a, b, 2005; Zhao and Tang 2007; Zheng and Tang 2007).

\footnotetext{
* Corresponding author

E-mail: lingzistdl@126.com
}

To date, the most typical optical sensors for Chl a survey are the SeaWiFS sensor and Moderate Resolution Imaging Spectroradiometer (MODIS) sensor, and at present the National Aeronautics and Space Administration (NASA) adopted OC4v4 algorithm for the global SeaWiFS processing and OC3M for the global MODIS processing (Esaias et al. 1998; McClain et al. 1998; O’Reilly et al. 2000). Global algorithms for satellite remote sensing do not always provide reasonable retrievals in all areas of the ocean, because an empirical algorithm is only as good as the data it is based on, and on how representative the data are of the environment or bio-optical provinces where the algorithm is to be applied (IOCCG 2006). Evaluation and validation of algorithms in regional sea area always show that revised or new algorithms in regional sea are necessary (D'Ortenzio 
et al. 2002; Iluz et al. 2003; Darecki and Stramski 2004). Previous work showed that both SeaWiFS and MODIS Chl a data agreed with in situ measurements in most area of SCS, but to be noted that in situ Chl a values were higher $\left(>0.1 \mathrm{mg} \mathrm{m}^{-3}\right)$ in these study areas, i.e., along coastal area and near upwelling area (Tang et al. 2003; Zhang et al. 2006). There are few comparisons between SeaWiFS, MODIS products and in situ data in oligotrophic area in NSCS (Chl a $\left.<0.1 \mathrm{mg} \mathrm{m}^{-3}\right)$.

Due to the oligotrophic characteristics of SCS, especially during the summer season (Chen et al. 2004; Chen et al. 2006), the available satellite algorithms may have their limits (Hooker and McClain 2000). Consequently, amendments to the global empirical algorithms of satellite were made and new regional ocean color algorithms were proposed for NSCS (Wu et al. 2004; Xu et al. 2007). In this work, the performance of three globally empirical algorithms (two for SeaWiFS, one for MODIS), and one regional algorithm (OC2_D'Ortenzio for the Mediterranean Sea) in the NSCS are evaluated. Our in situ data set are used to generate regional algorithms and compare their performances with NASA's operational algorithms and the regional algorithm for the Mediterranean Sea. Our study can present an independent analysis of SeaWiFS and MODIS Chl a data in NSCS.

\section{STUDY AREA, DATA, AND METHODS}

\subsection{Study Area}

The SCS, located along the tropical-subtropical rim of the western North Pacific Ocean and connecting Pacific Ocean and Indian Ocean, is one of the largest marginal seas in the world. It connects to the western Philippine Sea through the Luzon Strait (LS) and the East China Sea through the Taiwan Strait (TWS), and covers a total area of about 3.5 million $\mathrm{km}^{2}$ from the equator to $23^{\circ} \mathrm{N}$ and from 99 to $121^{\circ} \mathrm{E}$ with an average depth of $2000 \mathrm{~m}$ (Fig. 1)(Su 2004).

The SCS is a predominantly oligotrophic and ultra-oligotrophic basin (Chen et al. 2004; Chen et al. 2006). However, higher biomass may seasonally and locally occur in regions affected by sea surface temperature, monsoon and river runoff or upwelling (Tang et al. 2002, 2004, 2006). It is dominated by strong northeasterly monsoon during winter and southwesterly monsoon in summer (Liu and Xie 1999), and the monsoons always play an important role in the dynamics of upper circulations of SCS throughout the year (Wyrtki 1961). The SCS is strongly affected by industrial emissions from the northern border and exhibits high $\mathrm{Chl}$ a concentration along the coast (Zhao et al. 2005), and aerosol optical thickness of NSCS exhibits obvious and extreme di-

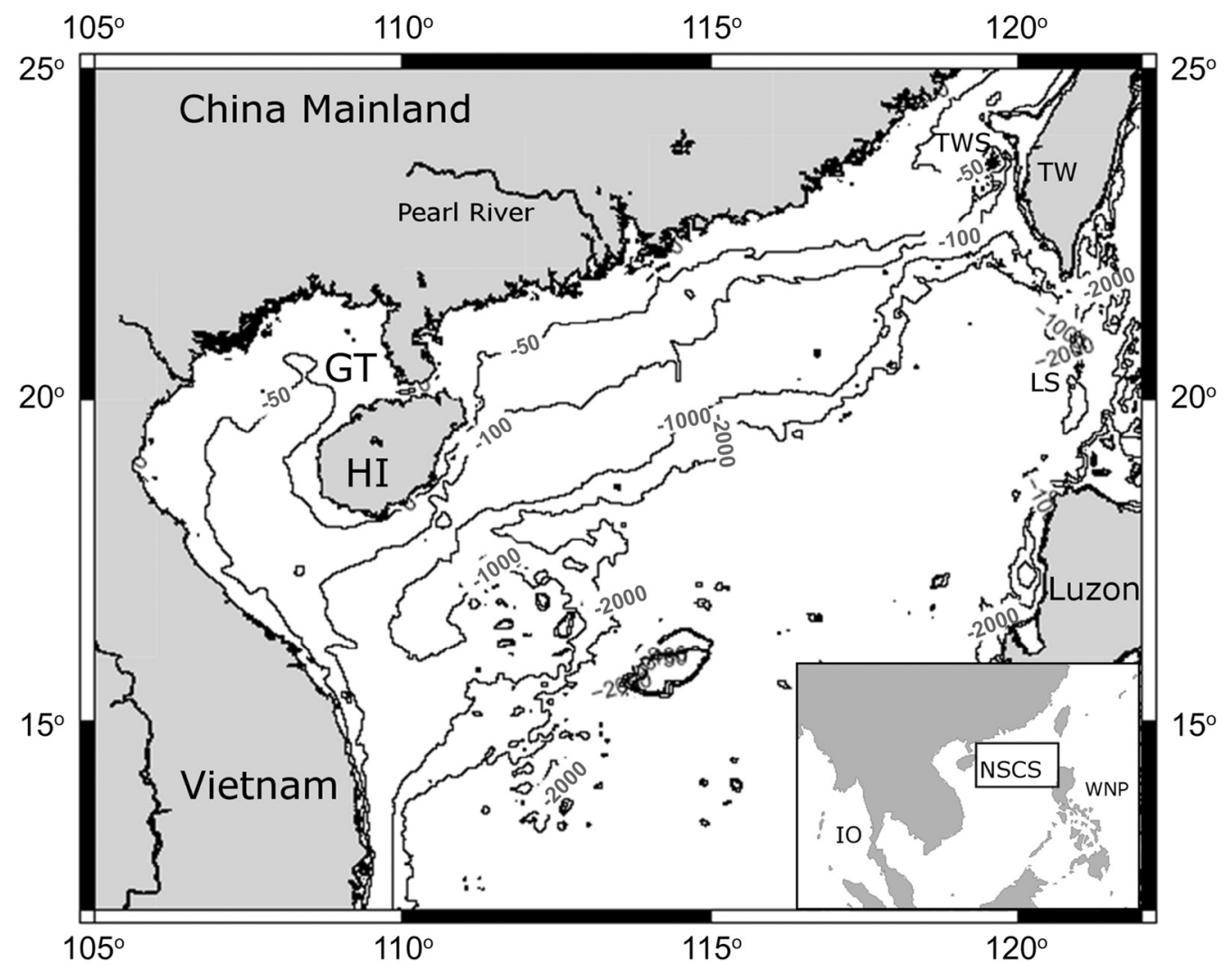

Fig. 1. Map of the study area. Overlaid on the map are the bathymetry contours (unit: meter). GT: the Gulf of Tonkin; HI: Hainan Island; LS: Luzon Strait; TW: Taiwan; TWS: Taiwan Strait; WNP: western North Pacific; IO: Indian Ocean. 
urnal change (Liu et al. 2008). Furthermore, it is frequently subject to typhoons which means atmospheric condition is complicated (Elsner and Liu 2003; Wu et al. 2006; Zhao et al. 2007; Zheng and Tang 2007).

\subsection{In Situ Data Observation}

In situ data were collected during two research cruises in NSCS conducted in the summer of 2004 (from September 18 to October 8) and 2007 (from August 10 to 29). Water samples of $1000 \mathrm{ml}$ of surface water were collected from each station and filtered through $200 \mu \mathrm{m}$ mesh to remove large abiotic particles or zooplankton (Zhou et al. 2004). The samples were filtered again using $0.45 \mu \mathrm{m}$ cellulose filter papers for the extraction of plant pigments. The filter papers were then stored in $90 \%$ acetone for 24 hours in a dark shaded area at $4^{\circ} \mathrm{C}$. The spectral absorption of $\mathrm{Chl}$ a was measured following the Fluorometric method using the Turner- Design 10 Fluorometer (Parsons et al. 1984). The Chl a values were then calculated using the spectral information.

\subsection{Temporal and Spatial Considerations}

A rigorous comparison requires that in situ data be collected within \pm 2 - $3 \mathrm{~h}$ of the satellite overpass (Bailey et al. 2000). However, due to frequent cloud cover and rainfall in NSCS in summer, such matching data pairs are limited. Therefore we measure time differences of \pm 24 and $\pm 48 \mathrm{~h}$ to find the usable time difference between the matching pairs.

Satellite navigation may not be accurate to a pixel due to the noise (Patt 2002), therefore, a box of some number of pixels is defined, centered on the location of the in situ measurement, and Bailey and Werdell (2006) suggests a kernel of $5 \times 5$ ( 25 pixels). In this work, we do the comparisons between $1 \times 1$ pixel, $3 \times 3$, and $5 \times 5$ pixels to find a suitable box.

\subsection{Satellite Data Processing}

SeaWiFS daily Level 1A (L1A) data were downloaded from the NASA OceanColor Home Page (http://oceancolor. gsfc.nasa.gov/). They were processed up to Level 2 (L2) Chl a data to obtain remote sensing reflectance $\left(R_{\mathrm{rs}}\right)$ maps for the four available visible bands $(443,490,510$, and $555 \mathrm{~nm})$ using the SeaWiFS Data Analysis System (SeaDAS 5.4) software which implements a modified atmospheric correction method (Gordon and Wang 1994) and then mapped to a cylindrical equidistant projection at $\sim 1 \mathrm{~km} \mathrm{pixel}^{-1}$ resolution.

Daily MODIS/Aqua L1A data were obtained in the same way as SeaWiFS. They were first processed to the corresponding Level $1 \mathrm{~B}$ (L1B) data, and then to L2 products to obtain three available visible bands $(443,488$, and $551 \mathrm{~nm})$ using SeaDAS 5.4. These data were mapped in a manner similar to that used for SeaWiFS.

\subsection{Evaluation Analysis}

General comparison methods used in the validation analysis for SeaWiFS from NASA (http://seabass.gsfc. nasa.gov/seabasscgi/validation.cgi) and in recent literature (O'Reilly et al. 2000; Gregg and Casey 2004; Zhang et al. 2006) are employed to do the evaluation in this study. Parameters extracted from analyses include median ratio, median difference, root mean square log error (RMSE) and average difference (bias), which describe the fidelity of satellite data. Median ratio and median difference are expressed as:

Median Ratio $=\frac{\sum \frac{S}{I}}{n}$

Median Difference $=\frac{\sum \frac{a b s(S-I)}{I}}{n} \times 100$

RMS log error (RMSE) and average difference defined as:

$$
\begin{aligned}
& \text { RMSE }=\sqrt{\frac{\sum[\log (S)-\log (I)]^{2}}{n}} \\
& \text { Average Difference }=\frac{\sum[\log (S)-\log (I)]}{n}
\end{aligned}
$$

Where $S$ indicates satellite data, $I$ indicates in situ data, and $n$ is the number of samples. The RMSE is an estimate of the error of the satellite data set, the average difference is an estimate of the bias, and the coefficient of determination $\left(\mathrm{r}^{2}\right)$ from the correlation analysis indicates the covariance between the satellite data set and the in situ measurements. Because the natural distribution of $\mathrm{Chl}$ a is lognormal (Campbell 1995), both in situ and Satellite data should be logarithmically transformed (base 10) before comparison. The performance of the algorithms in NSCS can be then evaluated with those statistical analyses.

\section{RESULTS}

\subsection{Temporal and Spatial Considerations}

There were 40 stations monitored in the 2004 cruise and 56 stations in the 2007 cruise (Figs. 2a, b). From Fig. 2 we can see that low $\mathrm{Chl}$ a concentrations $\left(\leq 0.1 \mathrm{mg} \mathrm{m}^{-3}\right)$ present in most areas in the NSCS, especially in northwestern Luzon; high Chl a concentrations $\left(>0.5 \mathrm{mg} \mathrm{m}^{-3}\right)$ are observed in coastal waters and upwelling areas. Two in situ stations located in northwest Luzon show the lowest $\mathrm{Chl}$ a values of 0.003 and $0.005 \mathrm{mg} \mathrm{m}^{-3}$ (Figs. 2c, d), which are lower than $0.008 \mathrm{mg} \mathrm{m}^{-3}$ (O'Reilly et al. 2000), and two in situ stations located in the costal and upwelling area show higher Chl a values of $0.601,0.507 \mathrm{mg} \mathrm{m}^{-3}$ (Figs. 2c, d). Considering that such kind of $\mathrm{Chl}$ a data are unrepresenta- 

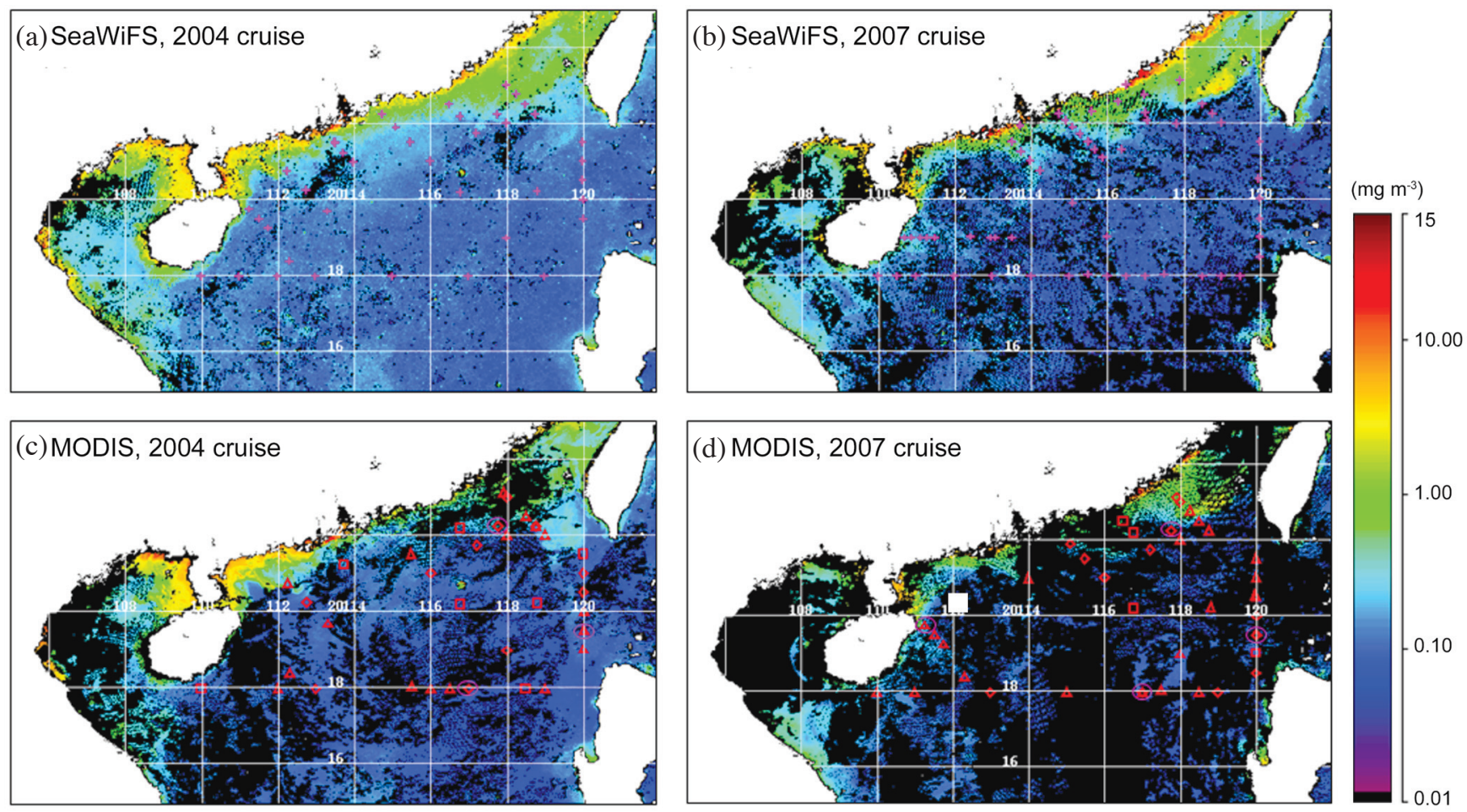

Fig. 2. Composite Chl-a images from SeaWiFS [(a) and (b)] and MODIS [(c) and (d)] for the two cruise periods in 2004 and 2007. 2004: September 18 - October 8; 2007: August 10 - 29. (a) 2004 SeaWiFS images, + mark 2004 in situ sampling stations; (b) 2007 SeaWiFS images, + mark 2007 in situ sampling stations; (c) 2004 MODIS images: Symbols mark the matching pairs of MODIS and in situ within the time difference of $\pm 3 \mathrm{~h}$ ( $\square$ ), $\pm 24 \mathrm{~h}(\diamond)$, and $\pm 48 \mathrm{~h}(\triangle)$; (d) 2007 MODIS images. Symbols mark the matching pairs of SeaWiFS and in situ within the time difference of $\pm 3 \mathrm{~h}$ $(\square), \pm 24 \mathrm{~h}(\diamond)$, and $\pm 48 \mathrm{~h}(\triangle)$. Stations encircled by $\bigcirc$ in (c) and (d) mean the in situ Chl-a values are below $0.01 \mathrm{mg} \mathrm{m}^{-3}$ and above $0.5 \mathrm{mg} \mathrm{m}^{-3}$.

tive and may induce great error in our comparison (IOCCG 2000), they are removed in advance.

There are only 4 matching pairs for SeaWiFS/in situ and 7 matching pairs for MODIS/in situ when considering the difference of $\pm 3 \mathrm{~h}$ (Figs. 2c, d). It is apparent that the matching pairs of $\pm 3 \mathrm{~h}$ are too few to do meaningful statistics. There are 17 matching pairs according to the time difference of $\pm 24 \mathrm{~h}$ for both SeaWiFS/in situ and MODIS/ in situ, and 36 pairs for SeaWiFS/in situ and 35 pairs for MODIS/in situ according to the time difference of $\pm 48 \mathrm{~h}$ (Figs. 2c, d). Statistics results are almost the same for SeaWiFS/in situ comparison according to the time difference of $\pm 24, \pm 48 \mathrm{~h}$, and small difference for MODIS/in situ comparison between time difference of \pm 24 and $\pm 48 \mathrm{~h}$ (Table 1). There are small difference between \pm 24 and $\pm 48 \mathrm{~h}$, in addition, more matching pairs may be advantageous to our algorithms evaluation, so we selected $\pm 48 \mathrm{~h}$ as the temporal considerations.

Statistical results of $1 \times 1$ pixel box are worse than the other two size of $3 \times 3$ and $5 \times 5$ pixels. The $\mathrm{r}^{2}$ of $1 \times 1$ pixel box are the lowest for both SeaWiFS and MODIS (Table 2), such results may be mainly caused by vibration due to noise. The results are almost the same for $3 \times 3$ and $5 \times 5$ pixels. According to the principle of less inaccuracy, $3 \times 3$ pixels is the suitable choice.

\subsection{Algorithm Presentation}

Four algorithms are selected for evaluation, including three empirical algorithms (OC2v4, OC4v4 for SeaWiFS, OC $3 \mathrm{M}$ for MODIS), and one regional algorithm proposed by D'Ortenzio for the Mediterranean Sea (Esaias et al. 1998; O'Reilly et al. 1998, 2000; D’Ortenzio et al. 2002). The formula of these algorithms and the numerical value of the coefficients are shown in Table 3 .

\subsection{Algorithm Evaluation and Adaptation}

Scatter plots of satellite versus in situ $\mathrm{Chl}$ a values for each selected algorithm $(\mathrm{OC} 4 \mathrm{v} 4, \mathrm{OC} 2 \mathrm{v} 2, \mathrm{OC} 2$ D'Ortenzio, and $\mathrm{OC} 3 \mathrm{M}$ ) are shown in Fig. 3, the median ratio, median difference (\%), slope, intercept, $\mathrm{r}^{2}, \mathrm{RMSE}$ and bias are listed in Table 4. Results show that algorithm OC2_D'Ortenzio has the highest fidelity with RMSE $=0.289$, median difference $=82.655$, slope $=1.403$, while the RMSE and Median difference values of the other three algorithms are all above 0.35 and 100 . The statistics parameters clearly show that all algorithms overestimate $\mathrm{Chl}$ a concentration except OC2_D'Ortenzio. OC2v4 has the largest overestimation because of the median difference $=217.909$ and median ratio $=3.179$. The $\mathrm{r}^{2}$ is almost identical for OC2v4 (0.734) 
Table 1. Comparison between satellite $\mathrm{Chl}$ a derived from the new algorithm and in situ $\mathrm{Chl}$ a according to the time difference of 24 and $48 \mathrm{~h}$.

\begin{tabular}{ccccccccccc}
\hline Satellite Sensor & Time Difference & $\mathbf{n}$ & Median Ratio & Median difference (\%) & Slope & Intercept & $\mathbf{r}^{2}$ & RMSE & Bias \\
\hline \multirow{2}{*}{ SeaWiFS } & $24 \mathrm{~h}$ & 17 & 2.941 & 199.984 & 2.041 & 0.007 & 0.752 & 0.469 & 0.365 \\
& $48 \mathrm{~h}$ & 36 & 2.841 & 186.912 & 2.190 & 0.005 & 0.791 & 0.449 & 0.375 \\
\multirow{2}{*}{ MODIS } & $24 \mathrm{~h}$ & 17 & 1.808 & 81.350 & 1.709 & 0.002 & 0.887 & 0.273 & 0.235 \\
& $48 \mathrm{~h}$ & 35 & 2.422 & 149.131 & 1.399 & 0.025 & 0.733 & 0.400 & 0.290 \\
\hline
\end{tabular}

Table 2. Comparison between satellite $\mathrm{Chl}$ a derived from the new algorithm and in situ Chl a according to the image pixel of $1 \times 1,3 \times 3$, and $5 \times 5$.

\begin{tabular}{ccccccccccc}
\hline Satellite Sensor & Pixel $\times$ Pixel & $\mathbf{n}$ & Median Ratio & Median difference (\%) & Slope & Intercept & $\mathbf{r}^{2}$ & RMSE & Bias \\
\hline SeaWiFS & $1 \times 1$ & 36 & 3.161 & 219.916 & 2.123 & 0.036 & 0.406 & 0.465 & 0.365 \\
& $3 \times 3$ & 36 & 2.841 & 186.912 & 2.190 & 0.005 & 0.791 & 0.449 & 0.375 \\
& $5 \times 5$ & 36 & 2.781 & 180.731 & 2.070 & 0.013 & 0.871 & 0.442 & 0.381 \\
MODIS & $1 \times 1$ & 35 & 2.299 & 137.201 & 0.966 & 0.055 & 0.577 & 0.384 & 0.269 \\
& $3 \times 3$ & 35 & 2.422 & 149.131 & 1.399 & 0.025 & 0.733 & 0.400 & 0.290 \\
& $5 \times 5$ & 35 & 2.444 & 149.572 & 1.371 & 0.030 & 0.752 & 0.400 & 0.298 \\
\hline
\end{tabular}

Table 3. Formulations of the empirical algorithms, published localized algorithms and new algorithms for the oligotrophic Northern South China Sea.

\begin{tabular}{|c|c|c|c|}
\hline Algorithm & Equation coefficients & $\mathbf{R}$ & Reference \\
\hline OC2v4 & $\begin{array}{l}C=10^{\left(a_{0}+a_{1} R+a_{2} R^{2}+a_{3} R^{3}\right)}+a_{4} \\
\mathrm{a}=[0.319,-2.336,0.879,-0.135,-0.071]\end{array}$ & $\log _{10}=\left(R_{r s} 490 / R_{r s} 555\right)$ & O'Reilly et al. 1998 \\
\hline OC4v4 & $\begin{array}{l}C=10^{\left(a_{0}+a_{1} R+a_{2} R^{2}+a_{3} R^{3}+a_{4} R^{4}\right)} \\
\mathrm{a}=[0.366,-3.067,1.930,0.649,-1.532]\end{array}$ & $\log _{10}\left(\frac{R_{r s} 443>R_{r s} 490>R_{r s} 510}{R_{r s} 555}\right)$ & O'Reilly et al. 2000 \\
\hline OC2v4_D'Ortenzio & $\begin{array}{l}C=10^{\left(a_{0}+a_{1} R+a_{2} R^{2}+a_{3} R^{3}\right)}+a_{4} \\
\mathrm{a}=[0.217,-2.728,0.704,0.297,-0.035]\end{array}$ & $\log _{10}=\left(R_{r s} 490 / R_{r s} 555\right)$ & D’Ortenzio et al. 2002 \\
\hline $\mathrm{OC} 2 \_\mathrm{TP} *$ & $\begin{array}{l}C=10^{\left(a_{0}+a_{1} R+a_{2} R^{2}+a_{3} R^{3}\right)}+a_{4} \\
\mathrm{a}=[0.1779,-1.393,1.882,-0.9575,-0.6149]\end{array}$ & $\log _{10}=\left(R_{r s} 490 / R_{r s} 555\right)$ & Present paper \\
\hline OC4_TP* & $\begin{array}{l}C=10^{\left(a_{0}+a_{1} R+a_{2} R^{2}+a_{3} R^{3}+a_{4} R^{4}\right)} \\
\mathrm{a}=[0.3439,-6.564,14,-15.61,6.255]\end{array}$ & $\log _{10}\left(\frac{R_{r s} 443>R_{r s} 490>R_{r s} 510}{R_{r s} 555}\right)$ & Present paper \\
\hline OC $3 \mathrm{M}$ & $\begin{array}{l}C=10^{\left(a_{0}+a_{1} R+a_{2} R^{2}+a_{3} R^{3}+a_{4} R^{4}\right)} \\
\mathrm{a}=[0.2830,-2.753,1.457,0.659,-1.403]\end{array}$ & $\log _{10}\left(\frac{R_{r s} 443>R_{r s} 488}{R_{r s} 551}\right)$ & O'Reilly et al. 2000 \\
\hline OC3M_TP* & $\begin{array}{l}C=10^{\left(a_{0}+a_{1} R+a_{2} R^{2}+a_{3} R^{3}+a_{4} R^{4}\right)} \\
\mathrm{a}=[0.144,-2.861,1.457,0.659,-1.402]\end{array}$ & $\log _{10}\left(\frac{R_{r s} 443>R_{r s} 488}{R_{r s} 551}\right)$ & Present paper \\
\hline
\end{tabular}


(a)

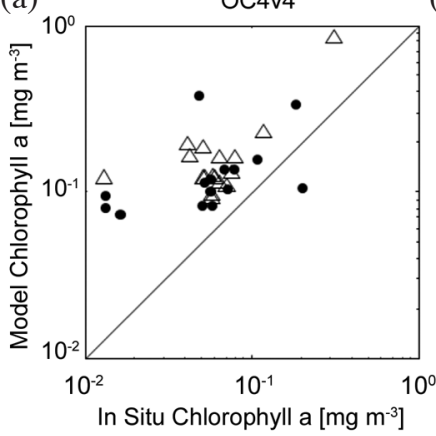

(e)

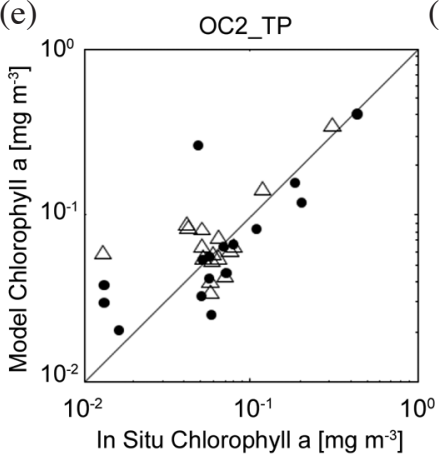

(b)

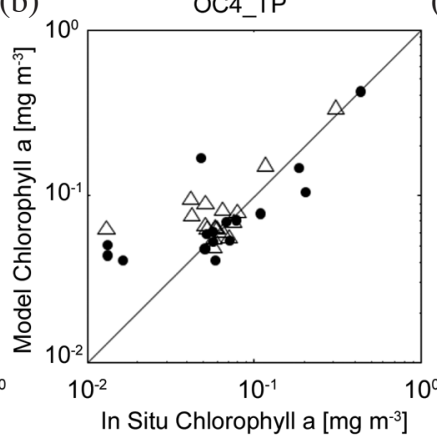

(f)

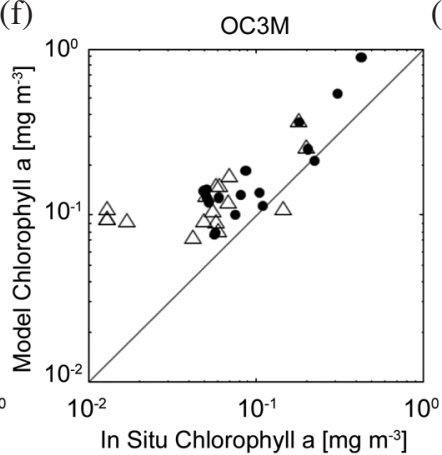

(c)

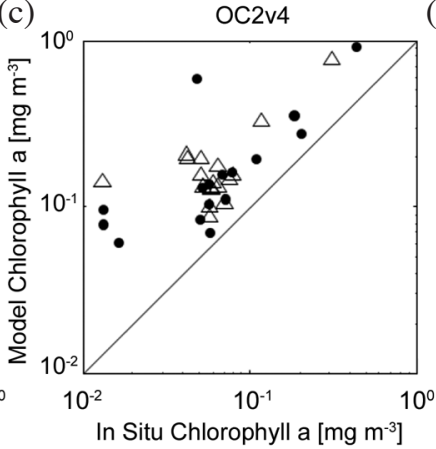

(g)

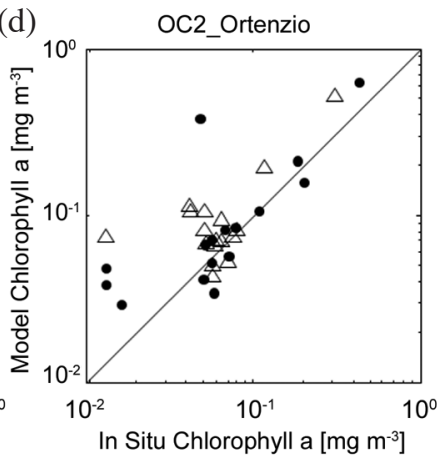

(d)

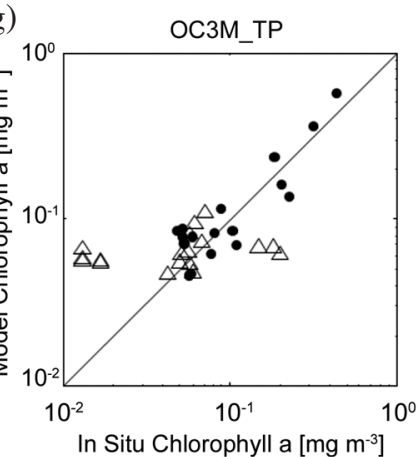

Fig. 3. Satellite Chl a estimates comparisons against in situ Chl a: (a) OC4v4; (b) OC4_TP; (c) OC2v4; (d) OC2_D’Ortenzio; (e) OC2_TP; (f) OC3M; (g) OC3M_TP. Signs indicate the time difference between in situ and satellite overpass: $\pm 24 \mathrm{~h}(\bullet)$ and $\pm 48 \mathrm{~h}(\triangle)$. Solid lines are $1: 1$ lines (TP: Tang \& Pan).

Table 4. Summary of the error analysis for the algorithms presented in Table 3.

\begin{tabular}{cccccccccc}
\hline Algorithm & $\mathbf{n}$ & Median Ratio & Median difference (\%) & Slope & Intercept & $\mathbf{r}^{2}$ & RMSE & Bias \\
\hline OC4v4 & 36 & 2.841 & 186.912 & 2.190 & 0.005 & 0.791 & 0.449 \\
OC2v4 & 36 & 3.179 & 217.909 & 1.958 & 0.042 & 0.734 & 0.483 & 0.420 \\
OC2_D'Ortenzio & 45 & 1.726 & 82.655 & 1.403 & 0.003 & 0.743 & 0.289 & 0.147 \\
OC4_TP & 36 & 1.463 & 58.669 & 0.885 & 0.018 & 0.840 & 0.245 & 0.095 \\
OC2_TP & 36 & 1.316 & 57.538 & 0.889 & 0.013 & 0.734 & 0.245 & 0.034 \\
OC3M & 35 & 2.422 & 149.131 & 1.399 & 0.025 & 0.733 & 0.400 & 0.290 \\
OC3M_TP & 35 & 1.508 & 72.127 & 0.989 & 0.007 & 0.731 & 0.288 & 0.086 \\
\hline
\end{tabular}

and OC3M (0.733), and the OC4v4 algorithm shows the highest $\mathrm{r}^{2}(0.791)$. We can see that OC4v4 performs better than $\mathrm{OC} 2 \mathrm{v} 4$ which is well known. A better performance is found with OC2_D'Ortenzio than OC2v4. The significant bias $(>0.1)$ of the retrieved data suggests, however, that it may be possible to improve the performance of these algorithms if we adapt the standard parameter values (the various regression coefficients) with new values determined from our field measurements in the NSCS.

Three new sets of coefficients are calculated by the non linear least squares method, trust region algorithm and then
OC4_TP, OC2_TP, and OC3M_TP algorithms are generated (Table 3). The comparisons between the three new models and the in situ Chl a data set show that the scatter plots are now distributed around the line of best agreement (Fig. 3). A good relationship can be seen between in situ and algorithm-derived Chl a concentration (Table 4): the slopes and $r^{2}$ are improved, generally, and the RMSE and bias are lower. The RMSE of three new algorithms are all within 0.35 , and the high accuracy are shown with bias $<0.1$, which is much better than the four evaluated algorithms. 


\section{DISCUSSION}

\subsection{Temporal and Spatial Selection}

Cloud cover is frequent especially during the summer season in NSCS because typhoons frequently occur with heavy cloud coverage (Wu et al. 2006). According to the time difference of $\pm 48 \mathrm{~h}$, the matching pairs in the 2004 cruise are 32 for SeaWiFS/in situ and 27 for MODIS/ in situ, respectively. The number of matching pairs is 8 for SeaWiFS/in situ and 11 for MODIS/ in situ in the 2007 cruise. The reason is probably due to fewer typhoons in the 2004 cruise than in the 2007 cruise (http://gis.typhoon.gov.cn/typhoonweb/). So a time difference of $\pm 48 \mathrm{~h}$ might be a reasonable choice in summer in NSCS (Zhang et al. 2006, 2007).

The spatial coverage includes moderately eutrophic coastal waters along Guangdong Province and Hainan Island, upwelling area in Taiwan Strait, and oligotrophic waters in the open area of NSCS (Fig. 2). In order to reduce the impact of geophysical variability a small box of $3 \times 3$ pixels is reasonable (Bailey and Werdell 2006).

\subsection{Comparison between Selected Algorithms and New Algorithms}

The results presented in the previous section raise the question of why the global empirical algorithms overestimate $\mathrm{Chl}$ a concentration but regional algorithm by D'Ortenzio show relatively better performance in NSCS.

One possible cause may be from our special in situ data set which covers a range spanning from very oligotrophic (the western area of the Luzon Strait) to eutrophic regimes (coastal and upwelling areas). Field $\mathrm{Chl}$ a values vary between 0.013 and $0.426 \mathrm{mg} \mathrm{m}^{-3}$, though low values $\left(<0.1 \mathrm{mg} \mathrm{m}^{-3}\right)$ are definitely more numerous $(\approx 77 \%)$. In summer $\mathrm{Chl}$ a concentration is lower than the other seasons because of the relatively high sea surface temperature, but strong offshore currents are often induced by southwesterly monsoons, and stronger wind-stress areas usually accord with higher Chl a concentration areas (Zhao et al. 2005). This kind of Chl a distribution may bring in situ data set that does not fit the data set of SeaWiFS Bio-optical Archive and Storage System (SeaBASS) which trend to be underrepresented in oligotrophic waters whereas overrepresented in mesotrophic and eutrophic regimes (O'Reilly et al. 1998). The other possible reason may be the errors in the atmospheric correction caused by aerosols (McClain et al. 2006). The aerosol optical thickness is the primary parameter in the atmospheric correction algorithm, however, the aerosol optical thickness of the NSCS in summer has an obvious diurnal change, and wind blowing from land induced by typhoons has an obvious influence on the aerosol optical thickness (Liu et al. 2008), which might induce more errors in the atmospheric correction.

The results show that OC2_D'Ortenzio plays a good role in NSCS. The reason appears firstly due to the fact that their low $\mathrm{Chl}$ a values $\left(<0.1 \mathrm{mg} \mathrm{m}^{-3}\right)$ are numerous $(\approx 70 \%)$ too. In this study the proportion of low $\mathrm{Chl}$ a concentration $\left(<0.1 \mathrm{mg} \mathrm{m}^{-3}\right)$ stands at about $77 \%$. Secondly, the aerosols are both from land (China Mainland at the northern border of NSCS, Europe at the northern border of the Mediterranean Sea)( D'Ortenzio et al. 2002) which can induce similar atmospheric correction errors.

\section{SUMMARY}

The major aim of this paper is the evaluation of four algorithms (OC2v4, OC4v4 and OC3M, NASA's operational algorithms and OC2_D'Ortenzio as an example of regional NSCS algorithms) in the Northern South China Sea during the summer season. Temporal and spatial considerations of $\pm 48 \mathrm{~h}$ and $3 \times 3$ pixels are determined, and evaluation results show a systematic overestimation of Chlorophyll a (Chl a) concentration by NASA global algorithms. The systematic misfit appears to be correlated with numerous $(\approx 77 \%)$ low Chl a concentration $\left(<0.1 \mathrm{mg} \mathrm{m}^{-3}\right)$ in our in situ data set and with imperfect atmospheric correction from aerosol optical thickness. Thus, based on our field data, we are not able to define which known algorithm should be preferred for the NSCS. For this reason we generated three amending algorithms, retrieved by fitting our NSCS in situ data set with OC2_like, OC4_like, and OC3M_like formula. The new TP series algorithms perform well with higher accuracy (bias $<0.1$ ) when applied to the in situ measurements.

Due to the relatively small number of available in situ data and the fact that our in situ data set only represents the oligotrophic ocean conditions in NSCS in the summer, the generated algorithms have to be considered to be very preliminary and deep research into the reasons of global algorithm misfit are still needed. A larger data set of bio-optical in situ measurements is useful and obviously necessary to produce a finely tuned algorithm for a region like SCS.

Acknowledgements This study was supported by the following research grants awarded to Professor Danling Tang: (1) The CAS/SAFEA International Partnership Program for Creative Research Teams (KZCX2-YW-T001); (2) Key Innovation Project of Chinese Academy of Sciences (kzcx2-yw-226 and LYQY200701); (3) National Natural Science Foundation of China (40976091, 40811140533); and (4) Natural Science Foundation of Guangdong (83510 30101000002). In situ data were obtained from open-cruises in 2004 and 2007 conducted by South China Sea Institute of Oceanology, Chinese Academy of Sciences; thanks to laboratory-mates Y. Q. Chen, S. F. Wang, H. Zhao, and Mr. J. L. Zhang and Dr. L. M. Huang of SCSIO for their help with in-situ data collection during the SCSIO open cruise. The authors are grateful to Y. Q. Chen for helping with making Fig. 1. 


\section{REFERENCES}

Bailey, S. W. and P. J. Werdell, 2006: A multi-sensor approach for the on-orbit validation of ocean color satellite data products. Remote Sens. Environ., 102, 12-23, doi: 10.1016/j.rse.2006.01.015. [Link]

Bailey, S. W., C. R. McCLain, P. J. Werdell, and B. D. Schieber, 2000: Normalized water-leaving radiance and chlorophyll a match-up analyses. In: Hooker, S. B. and E. R. Firestone (Eds.), NASA Tech. Memo. 2000206892 SeaWiFS postlaunch calibration and validation analyses, Part 2, Vol. 10, Greenbelt, Maryland: NASA Goddard Space Flight Center, 45-52.

Campbell, J. W., 1995: The lognormal distribution as a model for bio-optical variability in the sea. J. Geophys. Res., 100, 13237-13254, doi: 10.1029/95JC00458. [Link]

Chen, C. C., F. K. Shiah, S. W. Chung, and K. K. Liu, 2006: Winter phytoplankton blooms in the shallow mixed layer of the South China Sea enhanced by upwelling. J. Mar. Syst., 59, 97-110, doi: 10.1016/j.jmarsys.2005.09.002. [Link]

Chen, Y.-L. L., H. Y. Chen, D. M. Karl, and M. Takahashi, 2004: Nitrogen modulates phytoplankton growth in spring in the South China Sea. Cont. Shelf Res., 24, 527-541, doi: 10.1016/j.csr.2003.12.006. [Link]

D’Ortenzio, F., S. Marullo, M. Ragni, M. Ribera d'Alcala, and R. Santoleri, 2002: Validation of empirical SeaWiFS algorithms for chlorophyll-a retrieval in the Mediterranean Sea: A case study for oligotrophic seas. Remote Sens. Environ. , 82, 79-94, doi: 10.1016/S0034 -4257(02)00026-3. [Link]

Darecki, M. and D. Stramski, 2004: An evaluation of MODIS and SeaWiFS bio-optical algorithms in the Baltic Sea. Remote Sens. Environ., 89, 326-350, doi: 10.1016/j.rse.2003.10.012. [Link]

Elsner, J. B. and K. B. Liu, 2003: Examining the ENSOTyphoon Hypothesis. Clim. Res., 25, 43-54.

Esaias, W. E., M. R. Abbott, I. Barton, O. B. Brown, J. W. Campbell, K. L. Carder, D. K. Clark, R. H. Evans, F. E. Hoge, H. R. Gordon, W. M. Balch, R. Letelier, and P. J. Minnett, 1998: An overview of MODIS capabilities for ocean science observations. IEEE Trans. Geosci. Remote Sensing, 36, 1250-1265, doi: 10.1109/36.701076. [Link]

Gordon, H. R. and M. Wang, 1994: Retrieval of water-leaving radiance and aerosol optical thickness over the oceans with SeaWiFS: A preliminary algorithm. Appl. Optics, 33, 443-452, doi: 10.1364/AO.33.000443. [Link]

Gregg, W. W. and N. W. Casey, 2004: Global and regional evaluation of the SeaWiFS Chlorophyll data set. Remote Sens. Environ., 93, 463-479, doi: 10.1016/j.rse.20 03.12.012. [Link]

Hooker, S. B. and C. R. McClain, 2000: The calibration and validation of SeaWiFS data. Prog. Oceanogr., 45, 427-
465, doi: 10.1016/S0079-6611(00)00012-4. [Link]

Iluz, D., Y. Z. Yacobi, and A. Gitelson, 2003: Adaptation of an algorithm for chlorophyll-a estimation by optical data in the oligotrophic Gulf of Eilat. Int. J. Remote Sens., 24, 1157-1163, doi: 10.1080/0143116021000044797. [Link]

IOCCG, 2000: Sathyendranath, S. (Ed.), Remote Sensing of Ocean Color in Coastal, and Other Optically-Complex, Waters, Reports of the International Ocean-Color Coordinating Group, No. 3, IOCCG, Dartmouth, Canada, $145 \mathrm{pp}$.

IOCCG, 2006: Lee, Z. P. (Ed.), Remote Sensing of Inherent Optical Properties: Fundamentals, Tests of Algorithms, and Applications, Reports of the International OceanColor Coordinating Group, No. 5, IOCCG, Dartmouth, Canada, $122 \mathrm{pp}$.

Liu, D. Z., L. Q. Tian, J. K. Yang, and C. C. Chen, 2008: Study of aerosol optical thickness over Northern South China Sea. J. Trop. Meteorol., 24, 205-208. (in Chinese)

Liu, W. T. and X. Xie, 1999: Spacebased observations of the seasonal changes of South Asian monssons and ocanic responses. Geophys. Res. Lett., 26, 1473-1476, doi: 10.1029/1999GL900289. [Link]

McClain, C. R., M. L. Cleave, G. C. Feldman, W. W. Gregg, S. B. Hooker, and N. Kuring, 1998: Science quality SeaWiFS data for global biosphere research. Sea Technol., 39, 10-16.

McClain, C. R., S. B. Hooker, G. C. Feldman, and P. Bontempi, 2006: Satellite data for ocean biology, biogeochemistry, and Climate Research. Eos, Trans., AGU, 87, 337-343, doi: 10.1029/2006EO340002. [Link]

O'Reilly, J. E., S. Maritorena, B. G. Mitchell, D. A. Siegel, K. L. Carder, S. A. Garver, M. Kahru, and C. R. McClain, 1998: Ocean color chlorophyll algorithms for SeaWiFS. J. Geophys. Res., 103, 24937- 24953, doi: 10.1029/98JC02160. [Link]

O'Reilly, J. E., S. Maritorena, D. Siegel, M. C. O'brien, D. Toole, B. G. Mitchell, M. Kahru, F. P. Chavez, P. Strutton, G. Cota, S. B. Hooker, C. R. McClain, K. L. Carder, F. Muller-Karger, L. Harding, A. Magnuson, D. Phinney, G. F. Moore, J. Aiken, K. R. Arrigo, R. Letelier, and M. Culver, 2000: Ocean color chlorophyll a algorithms for SeaWiFS, OC2, and OC4: Version 4. In: Hooker S. B. and E. R. Firestone (Eds.), SeaWiFS Postlaunch Technical Report Series, SeaWiFS Postlaunch Calibration and Validation Analyses, Volume 11, Part 3, 9-23, Greenbelt, Maryland: NASA Goddard Space Flight Center, 1-51.

Parsons, T. R., Y. Maita, and C. M. Lalli, 1984: A Manual of Chemical and Biological Methods for Seawater Analysis, Oxford: Pergamon Press, 107-122.

Patt, F. S., 2002: Navigation algorithms for the SeaWiFS mission. NASA Tech. Memo., Vol. 206892, Greenbelt, 
MD: National Aeronautics and Space Administration, Goddard Space Flight Center.

Richardson, K. M., M. H. Pinkerton, P. W. Boyd, M. P. Gall, J. Zeldis, M. D. Oliver, and R. J. Murphy, 2004: Validation of SeaWiFS data from around New Zealand. Adv. Space Res., 33, 1160-1167, doi: 10.1016/ S0273-1177(03)00367-3. [Link]

Su, J., 2004: Overview of the South China Sea circulation and its influence on the coastal physical oceanography outside the Pearl River Estuary. Cont. Shelf Res., 24, 1745-1760, doi: 10.1016/j.csr.2004.06.005. [Link]

Tang, D. L., I. H. Ni, F. E. Müller-Karger, and Z. J. Liu, 1998: Analysis of annual and spatial patterns of CZCSderived pigment concentration on the continental shelf of China. Cont. Shelf Res., 18, 1493-1515, doi: 10.10 16/S0278-4343(98)00039-9. [Link]

Tang, D. L., D. R. Kester, I. H. Ni, H. Kawamura, and H. Hong, 2002: Upwelling in the Taiwan Strait during the summer monsoon detected by satellite and shipboard measurements. Remote Sens. Environ., 83, 457-471, doi: 10.1016/S0034-4257(02)00062-7. [Link]

Tang, D. L., H. Kawamura, M. A. Lee, and T. V. Dien, 2003: Seasonal and spatial distribution of chlorophyll- $a$ concentrations and water conditions in the Gulf of Tonkin, South China Sea. Remote Sens. Environ., 85, 475-483, doi: 10.1016/S0034-4257(03)00049-X. [Link]

Tang, D. L., H. Kawamura, T. V. Dien, and M. A. Lee, 2004a: Offshore phytoplankton biomass increase and its oceanographic causes in the South China Sea. Mar. Ecol.Prog. Ser., 268, 31-41, doi: 10.3354/meps268031. [Link]

Tang, D. L., H. Kawamura, H. Doan-Nhu, and W. Takahashi, 2004b: Remote sensing oceanography of a harmful algal bloom off the coast of southeastern Vietnam. J. Geophys. Res., 109, C03014, doi: 10.1029/20 03JC002045. [Link]

Tang, D. L., H. Kawamura, P. Shi, W. Takahashi, T. Shimada, F. Sakaida, and O. Isoguchi, 2006: Seasonal phytoplankton blooms associated with monsoonal influences and coastal environments in the sea areas either side of the Indochina Peninsula. J. Geophys. Res., 111, G01010, doi: 10.1029/2005JG000050. [Link]

Wu, J. Y., S. L. Shang, H. S. Hong, and Y. D. Zheng, 2004: An amendment to MODIS semianalytic algorithm based on the absorption measurements in the Pearl Riv- er estuary area. $A d v$. Mar. Sci., 22, 90-94. (in Chinese) Wu, D. S., W. Z. Feng, J. P. Xu, J. H. Yan, X. Zhao, J. W. Zhang, G. Y. Qiao, F. Lin, and C. M. Lv, 2006: The air-sea heat exchange during the onset of South China Sea monsoon in 1986. Chin. Sci. Bull., 51, 355-360. (in Chinese)

Wyrtki, K., 1961: Physical oceanography of the Southeast Asian waters. Naga Report, Volume 2, 195 pp.

Xu, D. Z., W. X. Cao, and G. F. Wang, 2007: A bio-optical model for retrieval of chlorophyll-a concentration in northern South China Sea. J. Trop. Oceanogr., 26, 1521. (in Chinese)

Zhang, C. G., Y. D. Zeng, X. Zhang, W. H. Pan, and J. Lin, 2007: Ocean chlorophyll a derived from satellite data with its application to red tide monitoring. J. Appl. Meteorol. Sci., 18, 821-831. (in Chinese)

Zhang, C., C. Hu, S. Shang, F. E. Müller-Karger, Y. Li, M. Dai, B. Huang, X. Ning, and H. Hong, 2006: Bridging between SeaWiFS and MODIS for continuity of chlorophyll- $a$ concentration assessments off Southeastern China. Remote Sens. Environ., 102, 250-263, doi: 10.1016/j.rse.2006.02.015. [Link]

Zhao, H. and D. L. Tang, 2007: Effect of 1998 El Niño on the distribution of phytoplankton in the South China Sea. J. Geophys. Res., 112, C02017, doi: 10.1029/200 6JC003536. [Link]

Zhao, H., D. L. Tang, and S. F. Wang, 2005: Spatial distribution of Chlorophyll a concentration in summer in Northwest South China Sea and its response to oceanographic environmental factors. J. Trop. Oceanogr., 24, 31-38. (in Chinese)

Zhao, H., D. L. Tang, and Y. Wang, 2008: Comparison of phytoplankton blooms triggered by two typhoons with different intensities and translation speeds in the South China Sea. Mar. Ecol. Prog. Ser., 365, 57-65, doi: 10.3354/meps07488. [Link]

Zheng, G. M. and D. L. Tang, 2007: Offshore and nearshore chlorophyll increases induced by typhoon winds and subsequent terrestrial rainwater runoff. Mar. Ecol. Prog. Ser., 333, 61-74, doi: 10.3354/meps333061. [Link]

Zhou, W. H., X. C. Yuan, W. Y. Huo, and K. D. Yin, 2004: Distribution of chlorophyll a and primary productivity in the adjacent sea area of Changjiang River Estuary. Acta Oceanol. Sin., 26, 143-150. (in Chinese) 